Article

\title{
Fire Properties of Acrylonitrile Butadiene Styrene Enhanced with Organic Montmorillonite and Exolit Fire Retardant
}

\author{
Tudor Mihai Simionescu ${ }^{1}$, Alina Adriana Minea ${ }^{1}$ (D) and Paulo Nobre Balbis dos Reis ${ }^{2, *(D)}$ \\ 1 Faculty of Materials Science and Engineering, Technical University "Gheorghe Asachi" of Iasi, \\ 700050 Iasi, Romania; simionescutudormihai@gmail.com (T.M.S.); aminea@tuiasi.ro (A.A.M.) \\ 2 C-MAST, Department of Electromechanical Engineering, University of Beira Interior, \\ Calçada Fonte do Lameiro, 6201-100 Covilhã, Portugal \\ * Correspondence: preis@ubi.pt; Tel.: +351-275329948
}

Received: 22 November 2019; Accepted: 10 December 2019; Published: 11 December 2019

\begin{abstract}
In this paper an experimental investigation on fire retardancy of a new polymer nanocomposite derived from organic montmorillonite and exolit fire retardant in an acrylonitrilebutadiene-styrene copolymer by analyzing the flammability and fire behavior is described. The samples were prepared by melting and mixing nanocomposites and fire retardant in different concentrations in an acrylonitrile-butadiene-styrene base polymer. It was found that using only one component (organic montmorillonite or fire retardant) the burning stops in $10 \mathrm{~s}$ on the sample. Confirmation of synergy in flammability by combining both montmorillonite and flame retardants was noticed and is discussed regarding the flame-retardant mechanisms assessed by means of the Limiting oxygen index (LOI), UL 94, and cone-calorimeter methods. The acrylonitrilebutadiene-styrene preparation with $15-20 \mathrm{wt} \%$ fire retardant and $1-2 \mathrm{wt} \%$ organic montmorillonite reached a UL-94 V-0 classification, contrasting with the pure acrylonitrile- butadiene-styrene and the acrylonitrile-butadiene-styrene with $15 \mathrm{wt} \%$ fire retardant and acrylonitrile-butadiene-styrene with 1-2 wt\% organic montmorillonite formulations, which completely burned. Finally, the samples showed a very good synergy going to a higher reduction of the peak heat release rate and to a minimum mass reduction, as obtained from cone calorimeter tests.
\end{abstract}

Keywords: acrylonitrile-butadiene-styrene; limiting oxygen index (LOI); flame retardant; nanocomposites

\section{Introduction}

Polymers are known for relative high flammability, most often accompanied with the production of smoke during combustion. ABS (acrylonitrile-butadiene-styrene) generates heavy smoke and soot with lack of char formation. Consequently, improving the fire-retardant behavior of polymers is of critical importance for specialists. Many authors have combined ABS with different fire retardants [1-12] as well as different clays in order to enhance the synergy between the components [13]. One of the most used clays is the organic montmorillonite (OMT) [13].

Several researchers tried to reduce the polymers' combustibility by adding different fire retardants. For example, Pour et al. [14] added multilayer graphene particles in concentrations of up to $5 \%$ and noticed a reduction of $30 \%$ in the heat release rate of the polycarbonate ABS, while commercially available flame retardants for ABS are halogen and silicon-containing [15]. Nevertheless, the use of halogen containing fire retardants is rare at this moment due to their negative influence on human health and the environment [16-18]. Later there has been an increase in using montmorillonite due to its excellent compatibility with ABS (acrylonitrile-butadiene-styrene) was noticed by Bardziński [19]. 
On the other hand, one can use the organic modified montmorillonite (OMT) obtained by ion exchange between montmorillonite and $C_{16}$ in water, according to Gilman et al. [20]. Meri et al. [21] developed a mixture between polycarbonate, ABS, and montmorillonite nanocomposites obtained by melt compounding in a twin-screw extruder and noticed an increase in mechanical properties of the ABS. Khobragade [22] performed a review on flame retarding performance of different materials and concluded that triphenyl phosphate based materials are the most appropriate as fire retardants. However, it is indicated in the literature that the integration of a quite low quantity of nanoclay (organomodified) in the polymer matrix generates a protective layer throughout combustion [23-25]. In this context, the clay addition on the material surface acts as a shield that restricts the heat transfer into the material, as well as the volatilization of combustible degradation products and oxygen diffusion into the material [22]. Montmorillonite received lately increased attention due to its exclusive nanoscale layered structure and high aspect ratio, thus enhancing the mechanical, thermal and flame-retardant properties [22-25].

Xia et al. [26] performed an experimental study on fire behavior involving ABS, montmorillonite, and ammonium polyphosphate (APP) as fire retardant by melting at $175{ }^{\circ} \mathrm{C}$. A change in LOI (limiting oxygen index) values was observed on increasing the OMT content to $2 \%$ while on increasing it to higher values the benefits were not obvious. With this idea, the conclusion was that OMT alone cannot effectively enhance the flame retardancy of ABS [26]. Similar studies were conducted by Lu et al. [27], Despinasse and Schartel [28] and Yoon et al. [29], who also noticed that there was no noteworthy modification in flame retardancy for the mixtures containing only clays, indicating that another FR (fire retardant) is needed to be added to the material.

Multicomponent flame retardant systems containing aluminum diethylphosphinate (AlPi) in thermoplastic styrene-ethylene-butylene-styrene elastomers have been investigated in terms of oxygen index, UL 94, cone calorimeter, and mechanical testing by Langfeld et al. [30]. The authors found that, by adding the fire retardant, an oxygen index of up to $27 \mathrm{vol} \%$ was obtained together with a horizontal burn rating in UL 94 with immediate self-extinction and the peak heat release rate decreased by up to $85 \%$. As a conclusion, such AlPi based multicomponent systems have become a good alternative for fire retardant materials.

Ramani and Dahoe [31] studied the effect on flame retardancy on polycaprolactam composites with the combination of aluminum diethylphosphinate and organically modified montmorillonite nanoclay. The outcome of their study was that by combining both flame retardants, the result was an enhanced effect when compared with their application on a separate basis. Guo et al. [32] studied the influence of modified ammonium polyphosphate (APP) on the flame retardancy of wood floor composite by cone calorimetry and noticed a synergetic effect between APP and the composite followed by a good improvement on the overall flame retardancy of the multicomponent material. Similar results were outlined also by other research groups (please see for example Realinho et al. [1], Xia et al. [26], Lu et al. [27], Despinasse and Schartel [28], Ma et al. [33]).

Nevertheless, some contradictory information was found in the open literature, some authors noticed a decrease in thermal stability by adding OMT [29-36] while other experimental research proved a thermal stability enhancement $[37,38]$. An explanation for these contradictory results may be related to the nanoparticle dispersion in the polymer matrix, as well as with the nanoparticle dimensions and chemical compatibility.

Therefore, according to the literature recommendations, in this research a recycled ABS (reABS) was acquired and improved by adding $1 \%-2 \%$ organic montmorillonite and $15 \%-20 \%$ fire retardants. The nanometer sized montmorillonite clay particles can enhance surface integrity and provide advantages over the thermal properties of the composites, while the Exolit fire retardants $[1,6]$ are well known for their capability to decrease the heat released in a fire. These new developed materials were tested with regard to their fire properties by means of the Limiting oxygen index (LOI), UL 94, and cone calorimeter methods. The overall aim was to improve the global properties of ABS by taking into account two directions: costs (by replacing ABS with recycled: reABS) and fire behavior (by adding 
both OMT and FR (fire retardant) to get better fire resistant properties). This study is of relevance for many areas like the automotive industry, electronics, civil engineering etc due to the large usage of ABS for component manufacturing and due to this material exposure in a possible fire scenario.

\section{Materials and Methods}

An acrylonitrile-butadiene-styrene copolymer (ABS), with the commercial name of Rocadur RABS 52, was provided by S.C. Romcarbon S.A. (Buzău, România) in granule form with a density of $1.03 \mathrm{~kg} / \mathrm{m}^{3}$. Two phosphorus fire retardant (FR) additives were considered: an ammonium polyphosphate (APP), Exolit ${ }^{\circledR}$ AP422, and an aluminum diethylphosphinate (AlPi), Exolit ${ }^{\circledR}$ OP1230, both supplied, in the form of white powder, by Clariant (Germany) with the properties shown in Table 1, as per given by the manufacturer. The two FRs were used in manufacturing the samples in a 1:1 proportion, as was recommended by the manufacturer. In addition, nanoparticles of organic montmorillonite (OMT) with the name Shelsite 30B Montmorillonite Nanoparticles (Nanoshell) was used as clay for preparing the samples. The OMT properties are as follows: particle dimension-less than $80 \mathrm{~nm}$; purity-99\%, $\mathrm{pH}-8-9$; humidity-less than $2 \%$ and density-2.8 $\mathrm{g} / \mathrm{cm}^{3}$.

Table 1. Properties of fire retardant materials.

\begin{tabular}{ccc}
\hline & Exolit OP 1230 & Exolit AP 422 \\
\hline Chemical formula & {$\left[\left(\mathrm{C}_{2} \mathrm{H}_{5}\right)_{2} \mathrm{PO}_{2}\right]_{3} \mathrm{Al}$} & $\left(\mathrm{NH}_{4} \mathrm{PO}_{3}\right)_{\mathrm{n}}$ \\
Phosphor content, $\%$ & $23.3 \%-24 \%$ & $31 \%-32 \%$ \\
Humidity, $\%$ & $\max 0.2 \%$ & $\max 0.25 \%$ \\
Density, g/cm & 1.35 & 1.9 \\
Decomposing temperature, ${ }^{\circ} \mathrm{C}$ & $>300$ & $>275$ \\
Particle dimension & $20-40 \mu \mathrm{m}$ & $17 \mu \mathrm{m}$ \\
\hline
\end{tabular}

Several formulations were prepared (see Table 2) and all the materials were first dried at $100 \mathrm{C}$ for $24 \mathrm{~h}$ than were mixed at a blending temperature of $205^{\circ} \mathrm{C}$ in a Brabender mixing chamber (Brabender, Germany), with a rotating rate of $60 \mathrm{rpm}$ applied for $10 \mathrm{~min}$. The materials final composition was chosen according to the open literature [1-5] and with the scope to determine the most favorable minimum addition of OMT and fire retardants in order to get the best fire properties. The specific specimens used for further tests were obtained at $205^{\circ} \mathrm{C}$ in a Carver press over three minutes at a pressure of $50 \mathrm{~atm}$ and two minutes at $150 \mathrm{~atm}$. For better accuracy of results, 2-3 specimens were manufactured for each composition and tests were performed on 2-3 samples, while the average values were used for the results discussion.

Table 2. Prepared samples.

\begin{tabular}{ccccc}
\hline Specimen & $\begin{array}{c}\text { Recycled Acrylonitrile- } \\
\text { Butadiene-Styrene, } \\
\text { reABS } \\
\mathbf{( w t \% )}\end{array}$ & $\begin{array}{c}\text { Organic } \\
\text { Montmorillonite, } \\
\text { OMT } \\
(\mathbf{w t} \%)\end{array}$ & $\begin{array}{c}\text { Exolit OP 1230 } \\
\text { (wt\%) }\end{array}$ & $\begin{array}{c}\text { Exolit AP 422 } \\
\mathbf{( w t \% )}\end{array}$ \\
\hline reABS & 100.0 & - & - & - \\
reABS 1\% OMT & 99.0 & 1.0 & - & - \\
reABS 15\% FR & 85.0 & - & 7.5 & $7, .5$ \\
reABS 1\% OMT 15\% FR & 84.0 & 1.0 & 7.5 & 7.5 \\
reABS 1\% OMT 18\% FR & 81.0 & 1.0 & 9.0 & 9.0 \\
reABS 1\% OMT 20\% FR & 79.0 & 1.0 & 10.0 & 10.0 \\
reABS 2\% OMT & 98.0 & 2.0 & - & - \\
reABS 2\% OMT 15\% FR & 83.0 & 2.0 & 7.5 & 7.5 \\
reABS 2\% OMT 18\% FR & 80.0 & 2.0 & 9.0 & 9.0 \\
reABS 2\% OMT 20\% FR & 78.0 & 2.0 & 10.0 & 10.0 \\
\hline
\end{tabular}

Limiting Oxygen Index (LOI) of ABS and its nanocomposites were measured using an Oxindex type equipment manufactured by the Hungarian Polymer Research Institute in compliance with 
standards ASTM D2863 (i.e., Standard Test Method for Measuring the Minimum Oxygen Concentration to Support Candle-Like Combustion of Plastics (Oxygen Index)) and ISO 4589 (i.e., standard for Determination of burning behaviour by oxygen index). Tests were performed on sheets with a size of $120 \times 10 \times 4 \mathrm{~mm}^{3}$ and were based on the lowest oxygen gas concentration that still sustains combustion of the sample.

The UL-94 tests were performed according to Standard for Tests for Flammability of Plastic Materials for Parts in Devices and Appliances, (i.e., ASTM D3081 and ASTM D635, respectively) with sample dimensions of $120 \times 10 \times 4 \mathrm{~mm}^{3}$ under a flame of $50 \mathrm{~kW}$.

UL-94 test results are classified by burning rate, from the least flame-retardant to the highest one as [1-6]:

- HB: slow burning;

- V-2: burning stops in $30 \mathrm{~s}$ on a vertical sample; drops of flaming particles are allowed.

- V-1: burning stops in $30 \mathrm{~s}$ on a vertical sample; drops of particles permitted as long as they are not in flame.

- V-0: burning stops in $10 \mathrm{~s}$ on a vertical sample; drops of particles acceptable as long as they are not in flame.

- $\quad$ 5VB: burning stops in 60 s; no drops acceptable; samples may develop a hole.

- 5VA: burning stops in $60 \mathrm{~s}$; no drops permitted; samples may not present a hole.

The mass loss calorimeter tests were performed following the ISO 13927 procedures (i.e., standard for Plastics - Simple heat release test using a conical radiant heater and a thermopile detector) using an FTT cone calorimeter instrument made by FTT Inc (East Grinstead, UK). Square specimens $\left(100 \times 100 \times 4 \mathrm{~mm}^{3}\right)$ were covered in aluminum foil and were irradiated at a heat flux of $50 \mathrm{~kW} / \mathrm{m}^{2}$, conforming to a fire scenario. The heat release rate (HRR) and total heat release (THR) were determined. Additionally, heat release values and mass reduction were uninterruptedly logged throughout burning. The calibration was achieved prior to tests and the orifice plate coefficient (device specific) was calibrated with a methane burner.

Finally, a regression analysis was performed by fitting the experimental data in Table Curve 3D software [39] and an equation to fit all data was proposed, as is described further on.

\section{Results and Discussion}

The LOI and UL-94 tests results are summarized in Table 3 where it can be seen that adding solely $15 \%$ FR to the reABS affected the nanocomposites LOI, by increasing it by $7 \%$. Pure reABS showed an HB type behavior (i.e., slow burning) at burning and a LOI value of $18.5 \%$, which is in agreement with the studies conducted by Realinho et al. [1] and Jian et al. [6]. When the FR content was as low as $15 \mathrm{wt} \%$, the LOI value increased to $25.5 \%$ indicating a significant influence of FR on LOI (Limiting oxygen index).

Table 3. Limiting Oxygen Index (LOI) and UL 94 tests results.

\begin{tabular}{ccccc}
\hline Specimen & LOI [\%] & $\begin{array}{c}\text { Behavior at Burning after } \\
\text { First Ignition }\end{array}$ & Drop Type & UL 94 \\
\hline reABS & 18.5 & burnt completely & burning drops & HB \\
reABS 15\% FR & 25.5 & burned 10 s & burning drops & V-2 \\
reABS 1\% OMT & 20.8 & burnt completely & burning drops & HB \\
reABS 1\% OMT 15\% FR & 25.8 & burned 9 s & no burning drops & V-1 \\
reABS 1\% OMT 18\% FR & 27.7 & burned 2 s & no drops & V-0 \\
reABS 1\% OMT 20\% FR & 28 & burned 0 s & no drops & V-0 \\
reABS 2\% OMT & 22 & burnt completely & burning drops & HB \\
reABS 2\% OMT 15\% FR & 27 & burned 1 s & no drops & V-0 \\
reABS 2\% OMT 18\% FR & 28.3 & burned 0 s & no drops & V-0 \\
reABS 2\% OMT 20\% FR & 28.7 & burned 0 s & V-0 \\
\hline
\end{tabular}


The maximum LOI value observed, 28.7\%, was for the nanocomposites reABS $2 \%$ OMT $20 \%$ FR. Thereafter, the LOI value for the nanocomposite with $18-20 \mathrm{wt} \%$ FR was nearly constant while the influence of OMT is rather important. In addition, as can be seen from Table 3, the material composition plays an important role and there is a synergy between adding OMT and FR as is reported in the literature [13]. Adding just one component, OMT or FR, does not give a clear advantage on burning rate, as can be seen from Table 3, where better results in terms of burning are obtained for the samples with both OMT and FR. Furthermore, it can be noted that the addition of OMT maintains the reABS behavior at burning (i.e., HB-slow burning [6]), while the addition of $15 \%$ FR gets a V-2 rating. On the other hand, when the percentage of FR increases, the burning rate increased to V-0. The only exception is reABS 1\% OMT 15\% FR that obtained a V-1 score for the burning rate, even though the LOI result was rather good. In this context, the addition of both OMT and FR to enhance the reABS behavior at burning can clearly be recommended.

The cone calorimeter is the most significant bench scale tool in the fire testing area being the most helpful for fire safety researchers to quantitatively examine the materials flammability $[7,8]$. In this research, cone calorimetric tests were run with a heat flux of $50 \mathrm{~kW} / \mathrm{m}^{2}$ to investigate the fire performance of reABS and the respective configurations are reported in Table 2. The cone-calorimeter tests results are summarized in Table 4 and Figures 1-6, where:

- $\quad$ TTI is the time taken for the specimen to ignite at $50 \mathrm{~kW} / \mathrm{m}^{2}$ flux;

- THR is the total heat released per unit area during the entire test for the tested thickness of product;

- PHRR is the peak heat release rate;

- Residue is measured as percentage;

- Effective heat of combustion is the energy produced per $\mathrm{kg}$ of the product. It is averaged over the length of the test;

- FIGRA is the growth rate of the burning intensity, HRR, during a test and is calculated as the maximum value of the function (heat release rate)/(elapsed test time).

Table 4. Cone calorimeter test results.

\begin{tabular}{|c|c|c|c|c|c|c|}
\hline Specimen & $\begin{array}{c}\text { Total Heat Released } \\
\text { Per Unit Area, } \\
\text { THR }\left(\mathrm{MJ} / \mathrm{m}^{2}\right)\end{array}$ & $\begin{array}{c}\text { Peak Heat Release } \\
\text { Rate, } \\
\text { PHRR }\left(\mathbf{k W} / \mathbf{m}^{2}\right)\end{array}$ & $\begin{array}{l}\text { Time to } \\
\text { Ignition, } \\
\text { TTI (s) }\end{array}$ & $\begin{array}{l}\text { Residue } \\
\text { (wt\%) }\end{array}$ & $\begin{array}{l}\text { Time to } \\
\text { PHRR (s) }\end{array}$ & $\begin{array}{l}\text { Growth Rate of the } \\
\text { Burning Intensity, } \\
\text { FIGRA(W/s) }\end{array}$ \\
\hline reABS & 85.52 & 486.05 & 24 & 1.6 & 152 & 3.45 \\
\hline reABS $15 \%$ FR & 64.05 & 150.92 & 21 & 10.7 & 85 & 1.74 \\
\hline reABS $1 \%$ OMT & 82.73 & 364.38 & 23 & 4.1 & 182 & 2.23 \\
\hline reABS $1 \%$ OMT $15 \%$ FR & 71.06 & 139.75 & 28 & 13.5 & 429 & 0.38 \\
\hline reABS $1 \%$ OMT $18 \%$ FR & 67.37 & 128.14 & 33 & 13.1 & 430 & 0.34 \\
\hline reABS $1 \%$ OMT $20 \%$ FR & 62.54 & 132.76 & 42 & 17.7 & 464 & 0.33 \\
\hline reABS $2 \%$ OMT & 84.99 & 317.29 & 20 & 6.4 & 215 & 1.66 \\
\hline reABS $2 \%$ OMT $15 \%$ FR & 74.57 & 149.69 & 29 & 15.8 & 434 & 0.39 \\
\hline reABS $2 \%$ OMT $18 \%$ FR & 77.85 & 154.26 & 30 & 17.3 & 429 & 0.41 \\
\hline reABS $2 \%$ OMT $20 \%$ FR & 74.15 & 154.15 & 29 & 18.9 & 475 & 0.38 \\
\hline
\end{tabular}

In Table 4 , the average standard deviation of all measured mass loss calorimeter values are $\mathrm{TTI}= \pm 3 \mathrm{~s} ; \mathrm{PHRR}= \pm 30 \mathrm{~kW} / \mathrm{m}^{2} ;$ time of PHRR $= \pm 5 \mathrm{~s}$; and residue $= \pm 0.2 \%$. From Table 4 an improvement of the peak heat release rate (PHRR) is visible when the FR and OMT, or both, were added to the polymer. For example, a decrease around $263 \%$ was found for $1 \%$ OMT $+18 \%$ FR, even if the time to PHRR goes three times higher. This substantial decrease agrees with the open literature $[6,9,10]$. If one compares the experimental data with the state of the art, it can be seen that lower PHRR values were obtained also by other research groups (i.e., $1821 \mathrm{~kW} / \mathrm{m}^{2}$ in reference [1], $574 \mathrm{~kW} / \mathrm{m}^{2}$ in [9] and $930 \mathrm{~kW} / \mathrm{m}^{2}$ in ref. [6]) and the phenomenon can be explained by the reABS initial combustion process (i.e., from its preparation process). More exactly, the initial ignifugation of the recycled ABS clearly revealed the influence of the flame retardants incorporated into the material when they compared the thermal properties of pristine ABS and recycled ABS recovered from monitors, microphones, and mice [40]. Beigbeder et al. [41] analyzed recycled ABS using X-ray diffraction and they identified 
brominated flame retardants. Plus, the UL-94 test pointed out that recycled ABS obtained V-0 classification and they concluded that several kinds of flame retardants were used [41].

The decrease of PHRR when $1 \%$ and $2 \%$ OMT is added to the ABS was registered as $25 \%$ and $35 \%$ respectively. On the other hand, similar results were attained by Du et al. [42], who added 5\% of two types of montmorillonite organically modified and obtained a reduction of PHRR of $39 \%$ in the first case and $42 \%$ in the second case. They concluded that the process may be influenced by melt viscosity, degradation behavior, and char formation on the sample surface [42]. Therefore, the decrease in PHRR and the increase in TTI proves the synergy between these two components: OMT and FR.

Regarding the THR results, when $1 \%$ of OMT is added to reABS a decrease of $4 \%$ is noticed and this can be attributed to a better dispersability of OMT at lower weight concentrations, as reported also by Singh and Ghosh [11] and Wu and Lang [9]. Additionally, the experiments performed by Zhang et al. [43] showed a similar behavior of THR when 2\% triclay III (oligomerically-modified clay) and $6 \%$ of triclay III are added to the ABS matrix [38].

The time to ignition results are in line with the open literature $[1,9,11]$. For example, Realinho et al. [1] developed a composite with ABS and $25 \mathrm{wt} \%$ APP/AlPi and obtained TTI (i.e., for a $35 \mathrm{~kW} / \mathrm{m}^{2}$ flux) of $30 \mathrm{~s}$ for the pure ABS and $25 \mathrm{~s}$ for the composite. Wu et al. [9] obtained the same TTI for ABS as that determined in the current work.

As discussion, it can be seen that the TTI test results obtained for ABS in combination with FR are lower for both samples FR-reABS. Specifically, TTI for the reABS 15\% FR decreased by $3 \mathrm{~s}$ while Realinho et al. [1] registered a time for ABS $25 \%$ FR decrease of $5 \mathrm{~s}$, if compared to the TTI for ABS. This occurred due to the weak thermal stability of the FR (in special AlPi) that starts to decompose at a lower temperature than pure ABS [1]. Furthermore, the temperature of degradation of OMT is lower than that attained for ABS, as also Wang et al. [44] observed. Plus, it can see that even if OMT and FR are used separately, weaker TTI times are obtained, if compared with reABS. This appears due to the weak thermal stability of OMT and FR, while when these two components are used together a synergy between them occurs and TTI times of nanocomposites are improved. On the other hand, Zhang et al. [45] who used a cone calorimeter with a heat flux of $35 \mathrm{~kW} / \mathrm{m}^{2}$, obtained a time of ignition of $39 \mathrm{~s}$ for pristine ABS and $51 \mathrm{~s}$ for ABS with 30\% APP filler. Other researchers, as Wu et al. [46], obtained a TTI of $24 \mathrm{~s}$ for ABS with a $50 \mathrm{~kW} / \mathrm{m}^{2}$ external heat flux, which is in line with our result. A different TTI time for ABS shows that for a comprehensive approach, several factors have to be considered, as for example: the monomers (acrylonitrile, butadiene-styrene) concentration [47], the manufacturing method, the products supplier (i.e., with regard to their purity, chemical composition etc.) or the external heat flux value of the cone calorimeter.

When the residue values are discussed, one can say that the residues of particles act as barriers against heat transport and thus decrease the heating rates of the developed nanocomposites. Additionally, the multilayer silicate heat-shielding layer slows down the escape of volatile products generated from the degrading polymer, as was explained also by Pour et al. [14] and Qin et al. [16]. Precisely, Qin et al. [16] affirmed that the barrier effect of exfoliated layered silicates delays the thermal degradation in the nanocomposite, while Pour et al. [14] noticed the same behavior for graphene layers in an PC/ABS matrix. The same effect of the protective layer formed during combustion was observed by Du et al. [42] which compared two types of organically modified montmorillonite mixed in ABS and noticed similar PHRR for both cases.

From the results in Table 4 it may be seen that the residue increases by adding both OMT and FR to almost 19\%, larger values being obtained with the $\mathrm{wt} \%$ increase of both clay and fire retardant. Nevertheless, the addition of clay to the reABS results in a $155 \%-296 \%$ increase in the residue while on adding the Exolit mixture to the base composite, the residue increases to $560 \%$. Finally, the released heat versus time for reABS and when combined with OMT and FR is shown in Figure 1, while Figures 2 and 3 show the results for reABS with 1\% OMT and 2\% OMT with different percentages of fire retardant (from $15 \%-20 \%$ ). Overall, it can be affirmed that the reABS burning is faster and more violent and this is decreased by adding different amounts of OMT and FR. This behavior was also observed by 
Ma et al. [33] who added $2 \%$ montmorillonite in ABS and by Realinho et al. [1] who added $25 \mathrm{wt} \%$ FR in pristine ABS and obtained a four-times decrease of PHRR.

In Figure 1 it is possible to observe that $15 \%$ of FR dramatically decreases the heat release, while OMT is responsible for more modest decreases. In the first case, the FR delays the burning as a consequence of the char layer formation (i.e., the same phenomenon was acknowledged also by Realinho et al. [1]) while adding higher percentages of OMT decreases the heat release (delaying the maximum point) due to migration of the OMT to the specimen surface. This phenomenon was also encountered by other research groups who studied these nanocomposites (see for example $[1,42,44]$ ). As a further comment, Du et al. [42] who used 5\% modified montmorillonite + ABS, also observed that the montmorillonite tactoids have a tendency to accumulate together on the surface of the burning material and create a compact protective layer. The same phenomenon was noticed by Wang et al. [43] when they tested the thermal degradation of ABS $+5 \%$ OMT. They noticed that after pyrolysis the nanocomposite forms a char layer with a multi-layered carbonaceous-silicate structure that builds up on the surface of the material during burning and has the capacity to insulate the material and to slow down the volatile products [44]. According to Figure 3, the best results were achieved when both OMT and FR were used, due to the synergy between them in the process of the char progression.

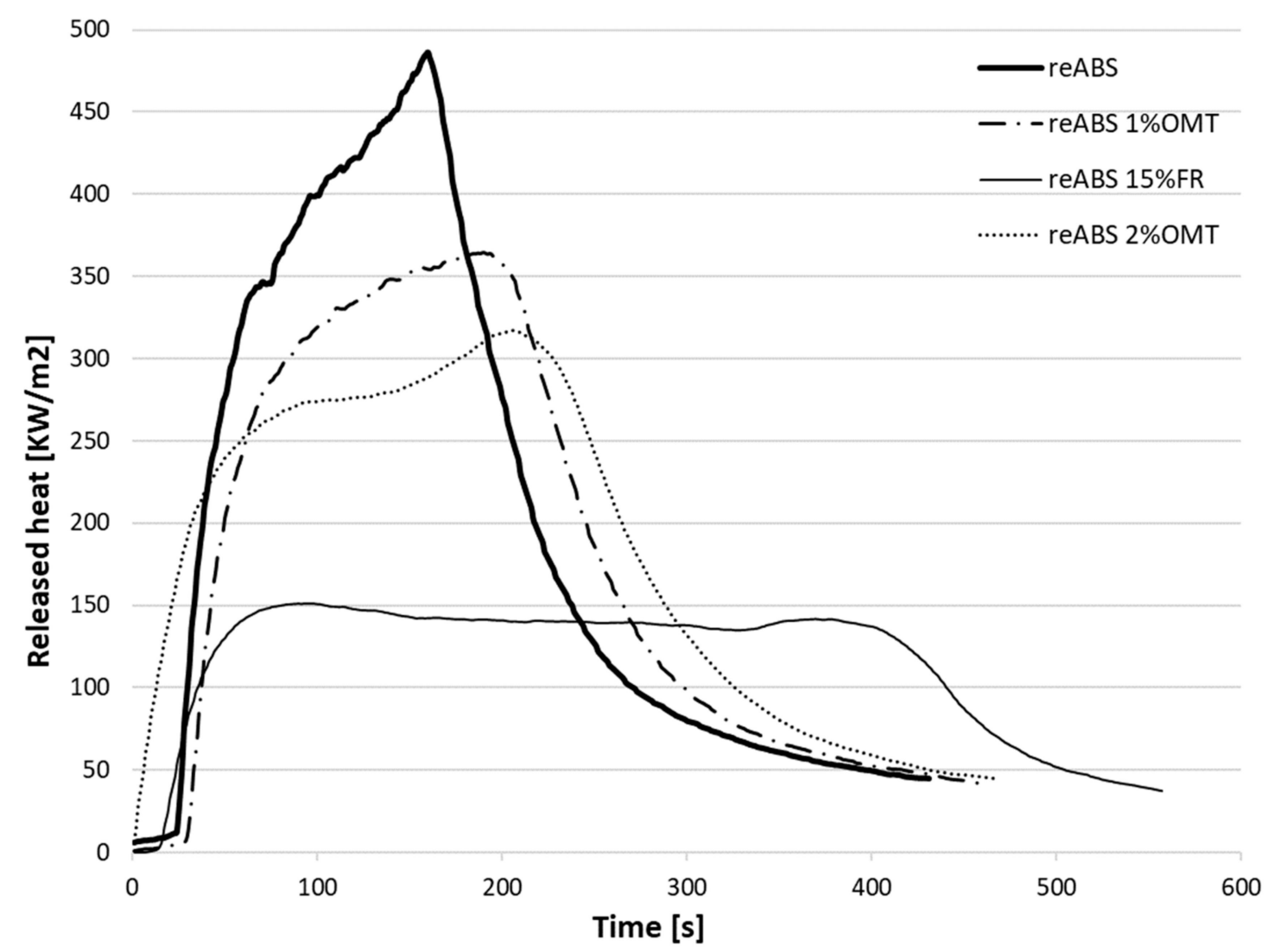

Figure 1. Released heat against time for reABS (recycled acrylonitrile-butadiene-styrene) and reABS with fire retardant (FR) and organic montmorillonite (OMT). 


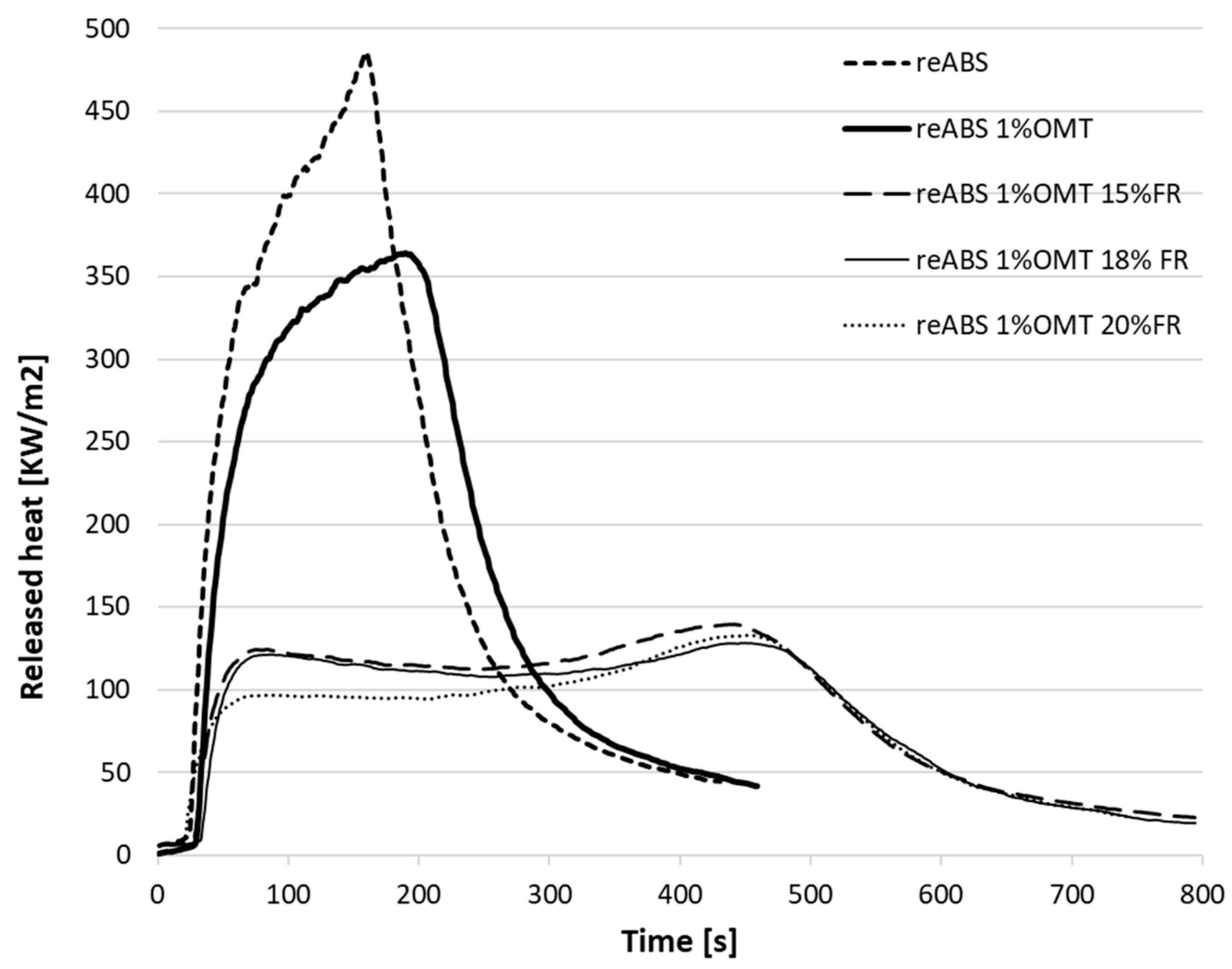

Figure 2. Released heat against time for reABS with 1\% OMT (organic montmorillonite) and different mass percentages of FR.

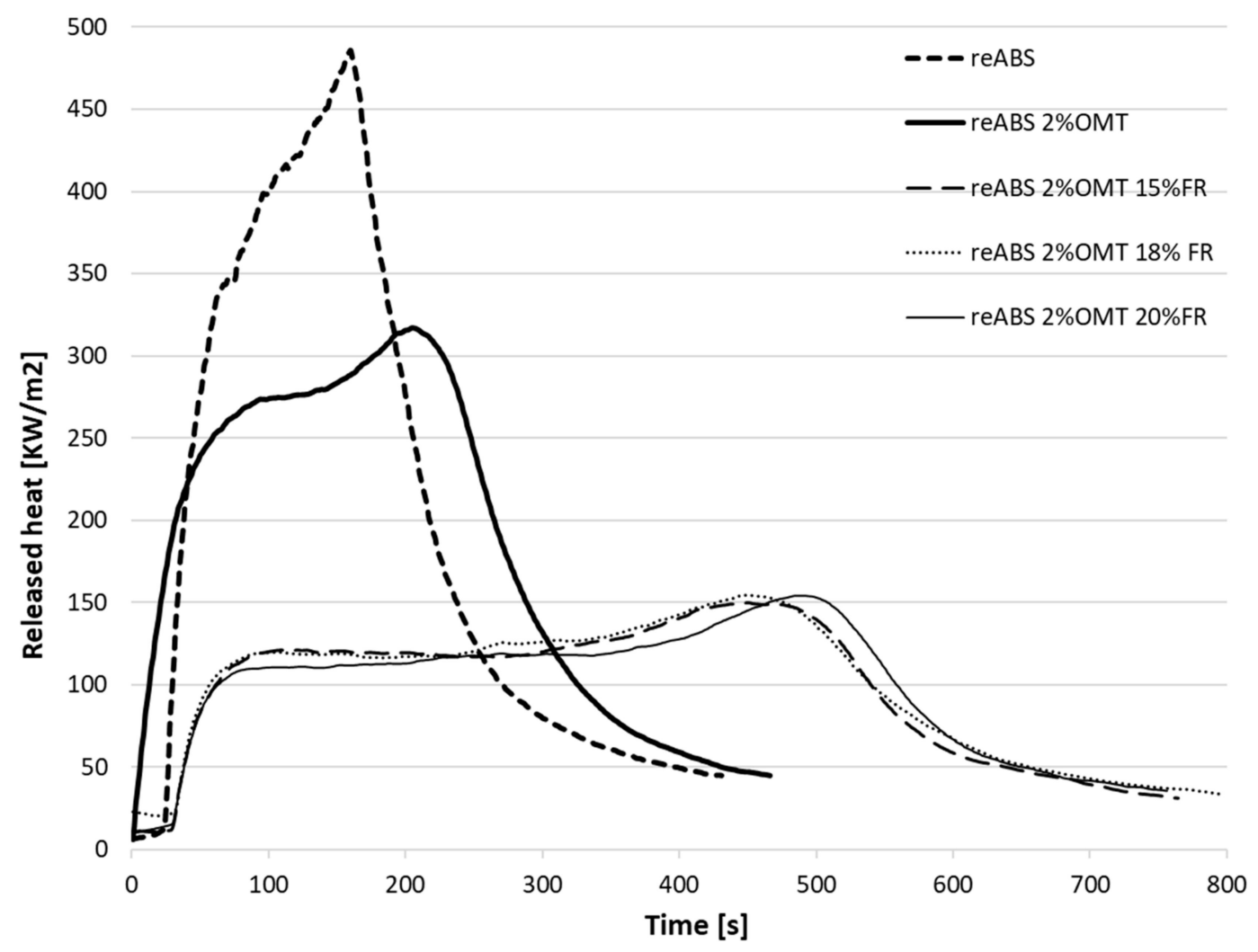

Figure 3. Released heat against time for reABS with $2 \%$ OMT and different mass percentages of FR. 
Figures 4-6 present the mass loss against time. It is possible to conclude that the reABS is burnt almost completely ( $98.4 \%$ mass loss) after a relatively short time in comparison with reABS with $15 \%$ FR which presents a double burning time and an $89.3 \%$ mass loss.

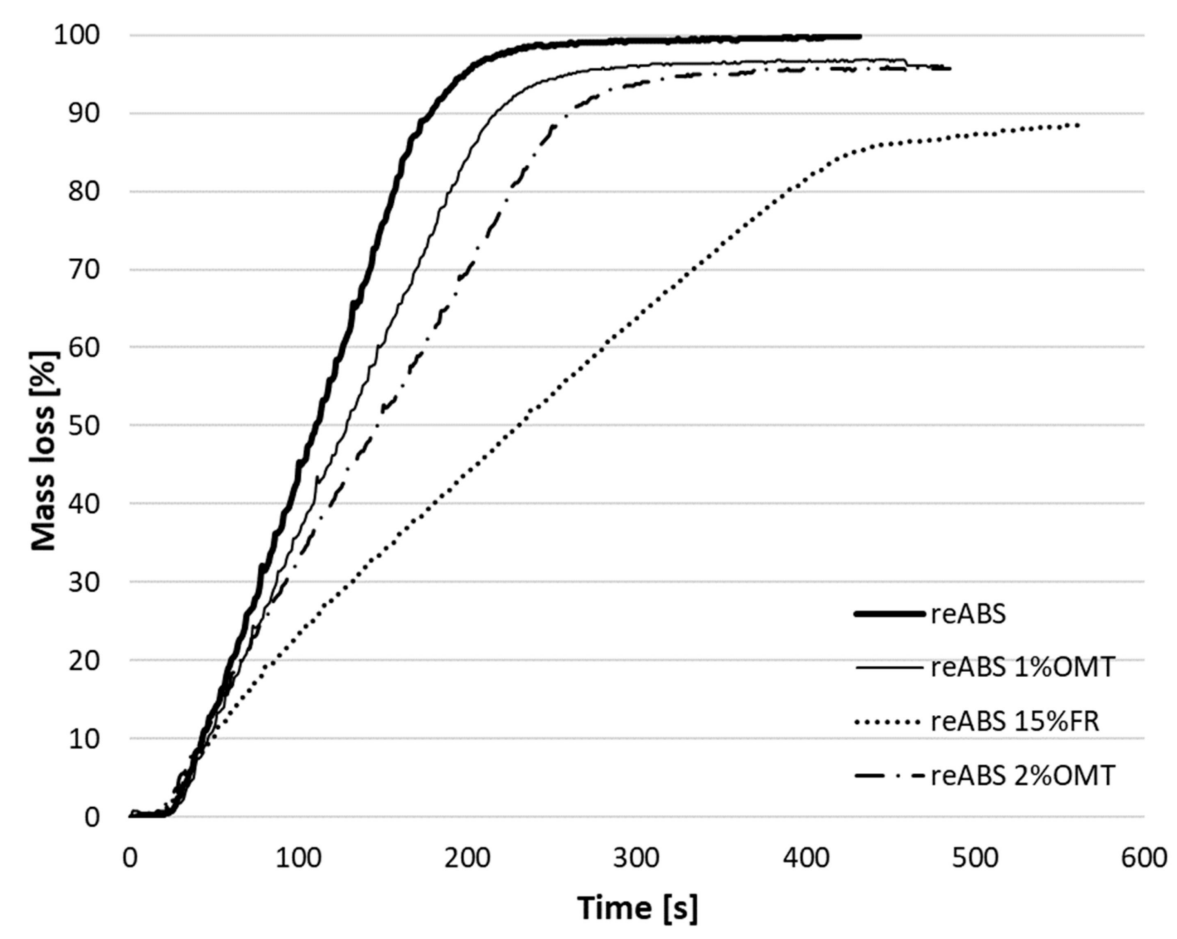

Figure 4. Mass loss against time for reABS with OMT and FR.

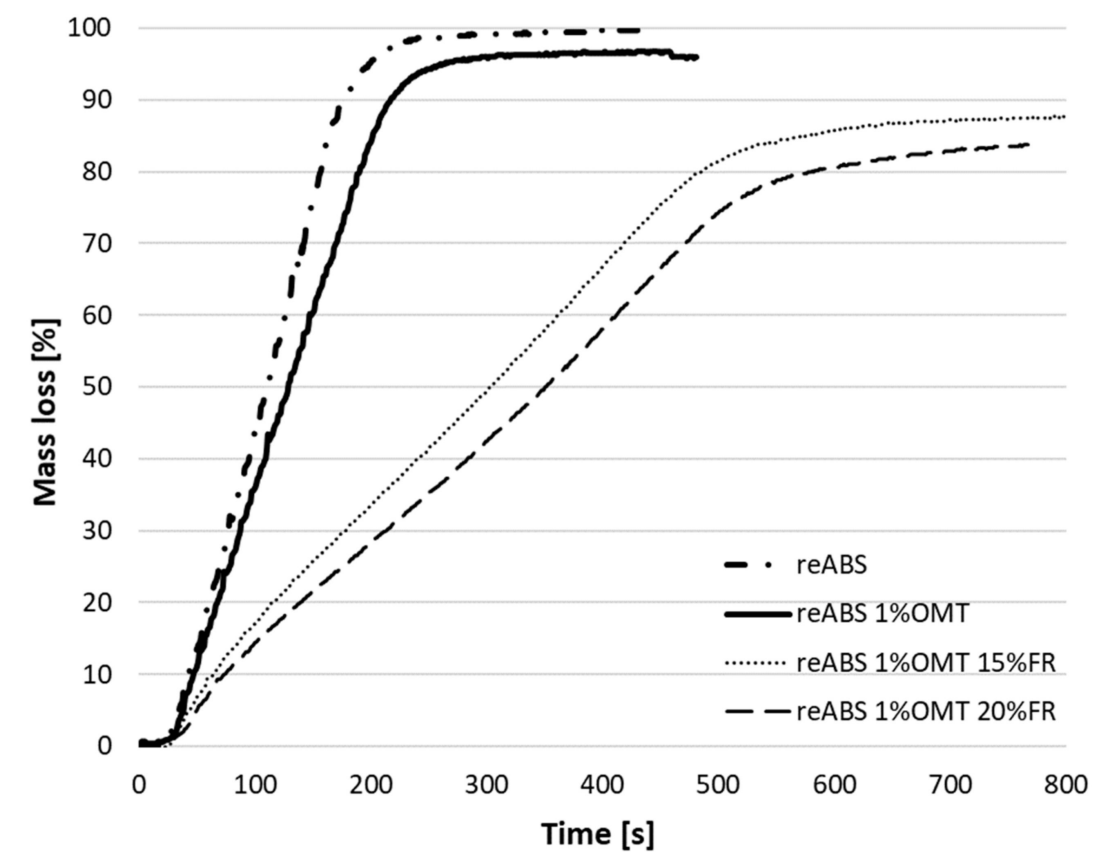

Figure 5. Mass loss against time for reABS with $1 \%$ OMT and different percentages of FR.

These results are in line with the outcomes of Realinho et al. [1] (i.e., a mass loss of $87.7 \%$ when $25 \%$ FR is added to pristine ABS). However, the influence of $1 \%-2 \%$ OMT is rather limited. Similar details are shown in Figures 5 and 6, where it can be clearly seen that the addition of FR greatly influences the mass loss reduction. More precisely, the decomposition time increases around $10 \%$ and $20 \%$ after 
adding $1 \%$ and $2 \%$ OMT, respectively, but when FR is added an increase of $200 \%$ is achieved in terms of decomposition time and $89.3 \%$ of the mass loss. In this case the mass loss is related to the released heat and fire propagation, as Gilman et al. [12] revealed in their study of materials with OMT and different fire retardants. Table 5 summarizes the results obtained from the figures for different times (after 100, 200, and 300 s), in order to evaluate the influence of OMT and FR on the reABS polymer.

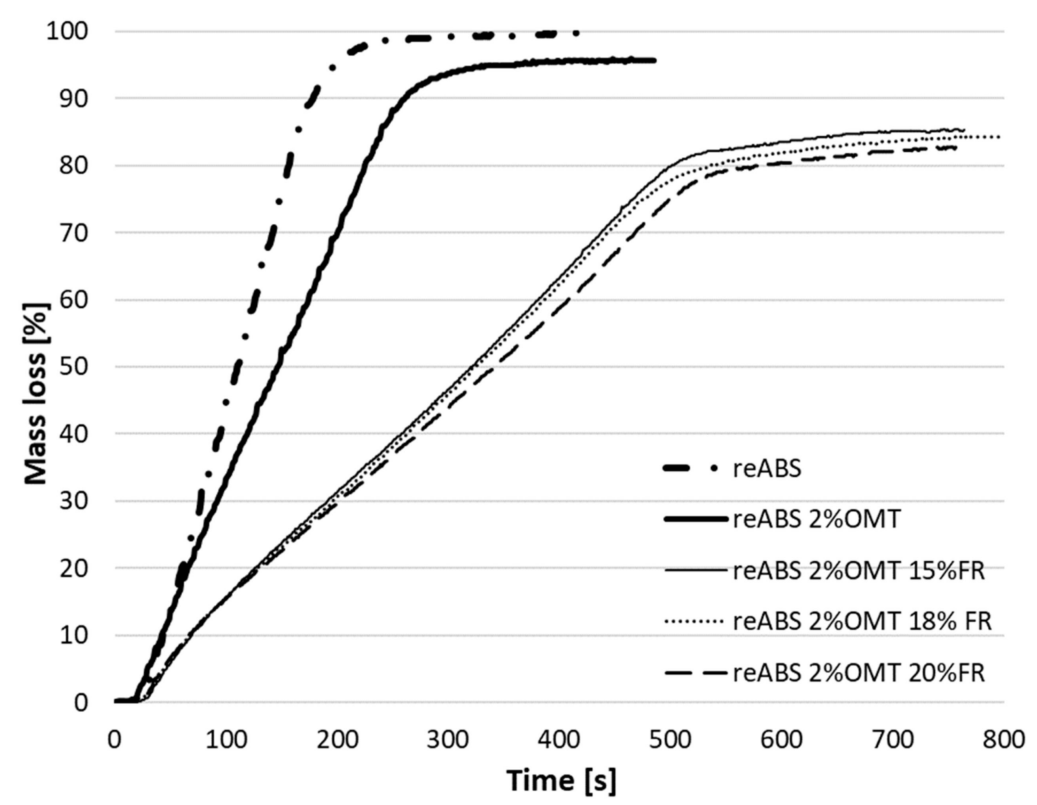

Figure 6. Mass loss against time for reABS with $2 \%$ OMT and different percentages of FR.

Table 5. Mass loss after different burning times.

\begin{tabular}{cccc}
\hline \multirow{2}{*}{ Specimen } & \multicolumn{3}{c}{ Mass after Burning [\%] } \\
\cline { 2 - 4 } & $\mathbf{1 0 0 ~ s}$ & $\mathbf{2 0 0 ~ s}$ & $\mathbf{3 0 0 ~ s}$ \\
\hline reABS & 55.03 & 4.35 & 0.74 \\
reABS 15\% FR & 76.34 & 55.79 & 35.99 \\
reABS 1\% OMT & 63.45 & 15.28 & 4.16 \\
reABS 1\% OMT 15\% FR & 82.39 & 66.29 & 50.45 \\
reABS 1\% OMT 18\% FR & 84.29 & 69.23 & 55.47 \\
reABS 1\% OMT 20\% FR & 85.49 & 71.44 & 57.35 \\
reABS 2\% OMT & 66.41 & 29.71 & 6.3 \\
reABS 2\% OMT 15\% FR & 84.17 & 68.37 & 53.2 \\
reABS 2\% OMT 18\% FR & 84.03 & 69.2 & 54.11 \\
reABS 2\% OMT 20\% FR & 84.33 & 70.13 & 55.95 \\
\hline
\end{tabular}

For example, the mass remaining after $300 \mathrm{~s}$ burning increases greatly when fire retardant and OMT are added, reaching a maximum mass of $57.35 \%$ of the initial weight for ABS $+1 \%$ OMT $+20 \%$ FR, while all samples with OMT and FR showed good firing behavior. The minimum decrease in the mass loss after $100 \mathrm{~s}$ burning was registered for reABS 1\% OMT 20\% FR (85.49\% from initial mass remains after burning), following the same trend as PHRR reduction. As a further observation, even if adding only OMT the mass loss decreases by about $5 \%$ and on adding solely FR, 35\% is obtained. Combining FR and OMT gave very good results in terms of burning behavior if the data from Table 5 are compared. Since the reduction in PHRR follows the reduction in mass loss rate, this correlation is essential to be noted [43].

Finally, another important parameter derived from the con-calorimeter test is the burning time that reflects the time needed for a specific material to decompose and to generate the volatile materials that sustain the burning process. Figure 7 presents the regression analysis of the experimental results 
where the influence on burning time of both the fire retardant and OMT concentration are evident. It can be seen that the influence of FR is bigger than that of OMT, although the best performance is obtained for reABS + OMT + FR (an increase of the burning time up to 30 times). In order to predict the total burning time for the different architectures studied, a regression was found with regard to Figure 7 (see the surface fit) and the following equation was obtained:

$$
t=251.33+65.61 \varphi_{O M T}+19.85 \varphi_{F R}
$$

where the $t$ is the burning time, in seconds, and $\varphi$ refers to the mass percentage of the nanoparticles of OMT and FR, respectively. The R-squared value for this correlation was calculated as 0.96 .

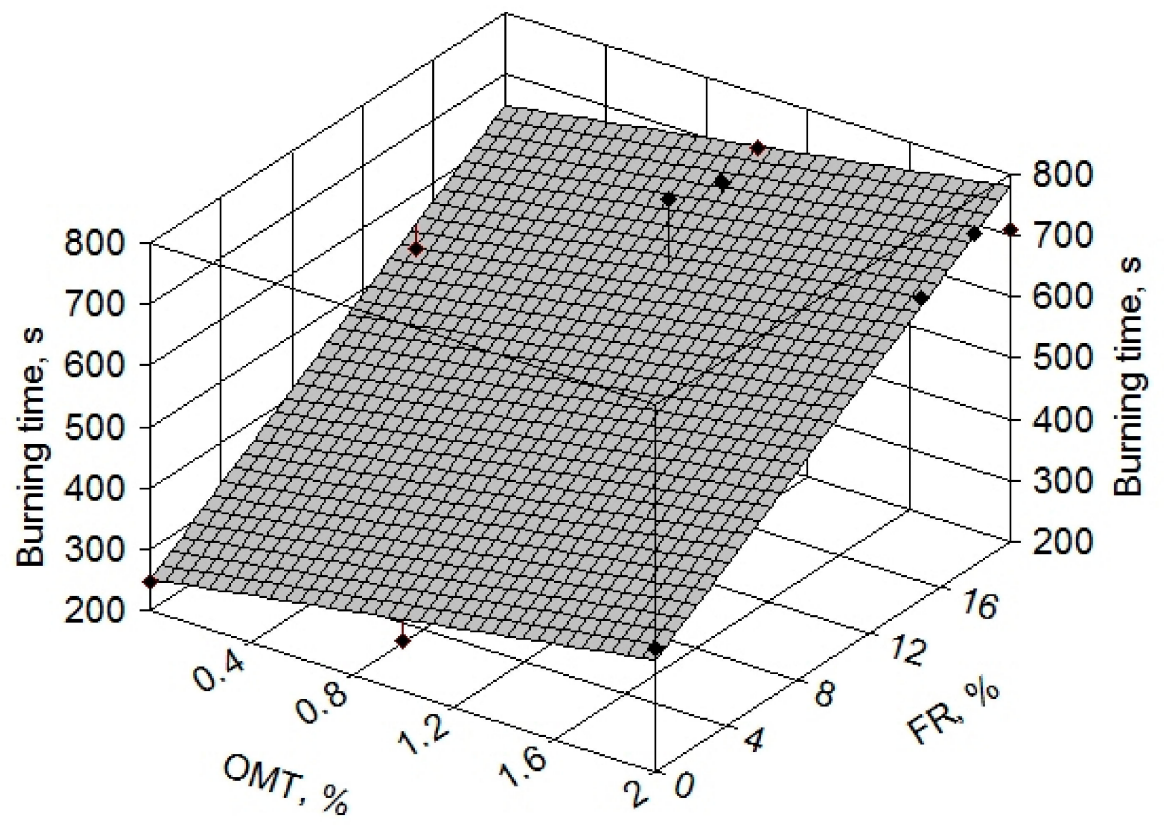

Figure 7. 3D analysis with regard to OMT and FR influence on the burning time.

Montmorillonite has a large industrial value due to its high aspect ratio, plate morphology intercalative capacity, natural abundance, and relatively low cost compared to other nanofillers that have higher price and more sensitive processing [48]. Nevertheless, as can be seen from the overall results from this research, adding small percentages of OMT obtains little benefit on the overall fire properties. On the other hand, a THR decrease of $7 \%$ of reABS+OMT samples, due to a better dispersability of OMT at lower weight concentrations was noticed by Simionescu and Minea [49] and also by Singh and Ghosh [11] and other research groups (see for example Wu and Lang, [9]). However, Zhuge et al. [50] incorporated montmorillonite into carbon nanofiber nano paper and noticed that THR decreased radically with the growing fraction of montmorillonite and attributed this phenomenon to the montmorillonite layer structure that functions as a barrier to mass and heat transfer. A similar occurrence was observed by Ahmed et al. [51] who added 1\%-3\% montmorillonite into polystyrene. Overall, the key effect of OMT is to improve the overall structure of the samples due to the interfacial intercommunication between the polymer matrix and the silicate layers of OMT [11], thus creating the basis for the reABS-OMT-FR synergy as a whole compound. The same synergetic effect was noticed also by other authors, as for example Wang and Wilkie [52] when discussing the utility of nanocomposites in fire retardancy in their comprehensive review.

\section{Conclusions}

OMT and a binary flame-retardant system based on Exolit were used in this paper to flame- retard reABS, and a high flame-retardant level was reached. 
Fundamentally, nine ABS flame retardant specimens were developed and the experimental study clearly showed improvements in terms of flame retardancy, such as reduction in peak heat release rate and total heat released compared with the pure reABS. Nevertheless, all formulations showed slightly lower values of time to ignition.

Based on flammability and fire tests of the ABS phosphorus flame retardant specimens, evidence of an important flame retardancy enhancement was noted when both flame retardants and montmorillonite were present in ABS. A combined gas and condensed-phase mode of action was observed during cone calorimeter tests, that led to the higher reduction of PHRR values, in good agreement with the obtained V0 classification under the UL-94 standard. In this context, a correlation was proposed to estimate the total burning time of a reABS-OMT-FR polymer nanocomposite. Finally, the cone calorimeter results revealed that both FR and OMT acted via flame inhibition and a protective flame-retardancy mechanism in the developed polymer nanocomposites.

To conclude, it can be affirmed that the developed and tested materials may constitute a viable alternative to common ABS (i.e., an opaque thermoplastic and amorphous polymer with many real life applications) for the manufacture of components for the automobile industry, as well as construction materials or other parts of domestic equipment (i.e., electronics, cases, toys etc.). The use of improved fire-resistant materials is very important, especially when a serious fire scenario may be involved. Nevertheless, more research is needed to establish the best and cheapest FR-OMT-ABS ratio to attain both economic advantages and an increased security in a fire incident.

Author Contributions: T.M.S. and A.A.M. conceived and designed the study, T.M.S. conducted the experiments and T.M.S. and A.A.M. analyzed the results. P.N.B.d.R. participated in the design and helped to draft the manuscript. T.M.S. and A.A.M. wrote the paper. All authors read and approved the final manuscript.

Funding: This research received no external funding.

Conflicts of Interest: Authors declare no conflict of interest.

\section{References}

1. Realinho, V.; Haurie, L.; Formosa, J.; Velasco, J.I. Flame retardancy effect of combined ammonium polyphosphate and aluminium diethyl phosphinate in crylonitrile-butadiene-styrene. Polym. Degrad. Stab. 2018, 155, 208-219. [CrossRef]

2. Tarantili, P.A. Composites of Engineering Plastics with Layered Silicate Nanofillers: Preparation and Study of Microstructure and Thermomechanical Properties. In Nanocomposites and Polymers with Analytical Methods; Cuppoletti, J., Ed.; IntechOpen: London, UK, 2011; ISBN 978-953-307-352-1.

3. Wang, S.; Hu, Y.; Lin, Z.; Gui, Z.; Wang, Z.; Chen, Z.; Fan, W. Flammability and thermal stability studies of ABS/Montmorillonite nanocomposite. Polym. Int. 2003, 52, 1045-1049. [CrossRef]

4. Weng, Z.; Wang, J.; Senthil, T.; Wu, L. Mechanical and thermal properties of ABS/montmorillonite nanocomposites for fused deposition modeling 3D printing. Mater. Des. 2016, 102, 276-283. [CrossRef]

5. Malas, A.; Pal, P.; Das, C.K. Effect of expanded graphite and modified graphite flakes on the physical and thermo-mechanical properties of styrene butadiene rubber/polybutadiene rubber (SBR/BR) blends. Mater. Des. 2014, 55, 664-673. [CrossRef]

6. Jian, R.-K.; Chen, L.; Chen, S.; Long, J.-W.; Wang, Y.-Z. A novel flame-retardant acrylonitrile-butadiene-styrene system based on aluminum isobutylphosphinate and red phosphorus: Flame retardance, thermal degradation and pyrolysis behavior. Polym. Degrad. Stab. 2014, 109, 184-193. [CrossRef]

7. Morgan, A.B.; Bundy, M. Cone calorimeter analysis of UL-94 V-rated plastics. Fire Mater. 2007, 31, $257-283$. [CrossRef]

8. Schartel, B.; Hull, T.R. Development of fire-retarded materials interpretation of cone calorimeter data. Fire Mater. 2007, 31, 327-354. [CrossRef]

9. Wu, N.; Lang, S. Flame retardancy and toughness modification of flame retardant polycarbonate/acrylonitrilebutadiene-styrene/AHP composites. Polym. Degrad. Stab. 2016, 123, 26-35. [CrossRef] 
10. Cao, X.; Yang, Y.; Luo, H.; Cai, X. High efficiency intumescent flame retardancy between Hexakis (4-nitrophenoxy) cyclotriphosphazene and ammonium polyphosphate on ABS. Polym. Degrad. Stab. 2017, 143, 259-265. [CrossRef]

11. Singh, P.; Ghosh, A.K. Torsional, tensile and structural properties of acrylonitrile-butadiene-styrene clay nanocomposites. Mater. Des. 2014, 55, 137-145. [CrossRef]

12. Gilman, J.W. Flammability and Thermal Stability Studies of Polymer Layered-Sili-cate (Clay) Nanocomposites. Appl. Clay Sci. 1999, 15, 31-49. [CrossRef]

13. Fontaine, P.G.; Gallos, A.; Bourbigot, S. Role of montmorillonite for enhancing fire retardancy of intumescent. In Proceedings of the Eleventh International Symposium on Fire Safety Science, Christchurch, New Zealand, 9-14 February 2014; pp. 808-820.

14. Pour, R.H.; Soheilmoghaddam, M.; Hassan, A.; Bourbigot, S. Flammability and thermal properties of polycarbonate/acrylonitrilebutadiene-styrene nanocomposites reinforced with multilayer grapheme. Polym. Degrad. Stab. 2015, 120, 88-97. [CrossRef]

15. Zhong, H.; Wei, P.; Jiang, P.; Wang, G. Thermal degradation behaviors and flame retardancy of PC/ABS with novel silicon-containing flame retardant. Fire Mater. 2007, 31, 411-423. [CrossRef]

16. Qin, H.; Zhang, S.; Zhao, C.; Hu, G.; Yang, M. Flame retardant mechanism of polymer/clay nanocomposites based on polypropylene. Polymer 2005, 46, 8386-8395. [CrossRef]

17. Levchik, S.V.; Weil, E.D. Overview of recent developments in the flame retardancy of polycarbonates. Polym. Int. 2005, 54, 981-998. [CrossRef]

18. Murashko, E.A.; Levchik, G.F.; Levchik, S.V.; Bright, D.A.; Dashevsky, S. Fire retardant action of resorcinol bis(diphenyl phosphate) in PC-ABS blend. II. Reactions in the condensed phase. J. Appl. Polym. Sci. 1999, 71, 1863-1872. [CrossRef]

19. Bardziński, P.J. On the impact of intermolecular interactions between the quaternary ammonium ions on interlayer spacing of quat-intercalated montmorillonite: A molecular mechanics and ab-initio study. Appl. Clay Sci. 2014, 95, 323-339. [CrossRef]

20. Gilman, J.W.; Jackson, C.L.; Morgan, A.B.; Harris, R., Jr.; Manias, E.; Giannelis, E.P.; Wuthenow, M.; Hilton, D. Flammability properties of polymer-layered silicate nanocomposites. Propylene and polystyrene nanocomposites. Chem. Mater. 2000, 12, 1866-1873. [CrossRef]

21. Meri, R.M.; Zicans, J.; Ivanova, T.; Berzina, R.; Saldabola, R.; Maksimovs, R. The effect of introduction of montmorillonite clay (MMT) on the elastic properties of polycarbonate (PC) composition with acrylonitrile-butadiene styrene (ABS). Compos. Struct. 2015, 134, 950-956. [CrossRef]

22. Khobragade, P.S.; Hansora, D.P.; Naik, J.B.; Chatterjee, A. Flame retarding performance of elastomeric nanocomposites: A review. Polym. Degrad. Stab. 2016, 130, 194-240. [CrossRef]

23. Pagacz, J.; Pielichowski, K. Preparation and characterization of PVC/Montmorillonite nanocomposites-A review. J. Vinyl Addit. Technol. 2009, 15, 61-76. [CrossRef]

24. Kader, M.A.; Kim, K.; Lee, Y.S.; Nah, C. Preparation and properties of nitrile rubber/montmorillonite nanocomposites via latex blending. J. Mater. Sci. 2006, 41, 7341-7352. [CrossRef]

25. Zhang, Y.; Zhu, W.; Lu, Y.; Gao, Z.; Gu, J. Nano-scale blocking mechanism of MMT and its effects on the properties of polyisocyanate-modified soybean protein adhesive. Ind. Crops Prod. 2014, 57, 35-42. [CrossRef]

26. Xia, Y.; Jian, X.; Li, J.; Wang, X.; Xu, Y. Synergistic effect of montmorillonite and intumescent flame retardant on flame retardancy enhancement of ABS. Polym. Plast. Technol. Eng. 2007, 46, 227-232. [CrossRef]

27. Lu, C.; Liu, L.; Chen, N.; Wang, X.; Yang, D.; Huang, X.; Yao, D. Influence of clay dispersion on flame retardancy of ABS/PA6/APP blends. Polym. Degrad. Stab. 2015, 114, 16-29. [CrossRef]

28. Despinasse, M.C.; Schartel, B. Aryl phosphateearyl phosphate synergy in flame-retarded bisphenol A polycarbonate/acrylonitrile-butadiene-styrene. Thermochim. Acta 2013, 563, 51-61. [CrossRef]

29. Yoon, P.J.; Hunter, D.L.; Paul, D.R. Polycarbonate Nanocomposites Part 1. Effect of Organoclay Structure on Morphology and Properties. Polymer 2003, 44, 5323-5339. [CrossRef]

30. Langfeld, K.; Wilke, A.; Sut, A.; Greiser, S.; Ulmer, B.; Andrievici, V.; Limbach, P.; Bastian, M.; Schartel, B. Halogen-free fire retardant styrene-ethylene-butylene-styrene-based thermoplastic elastomers using synergistic aluminum diethylphosphinate-based combinations. J. Fire Sci. 2015, 33, 157-177. [CrossRef]

31. Ramani, A.; Dahoe, A.E. On flame retardancy in polycaprolactam composites by aluminium diethylphosphinate and melamine polyphosphate in conjunction with organically modified montmorillonite nanoclay. Polym. Degrad. Stab. 2014, 105, 1-11. [CrossRef] 
32. Guo, C.; Zhou, L.; Lv, J. Effects of expandable graphite and modified ammonium polyphosphate on the flame-retardant and mechanical properties of wood flour-polypropylene composites. Polym. Polym. Compos. 2013, 21, 449-456. [CrossRef]

33. Ma, H.; Tong, L.; Xu, Z.; Fang, Z. Intumescent flame retardant-montmorillonite synergism in ABS nanocomposites. Appl. Clay Sci. 2008, 42, 238-245. [CrossRef]

34. Yoon, P.J.; Hunter, D.L.; Paul, D.R. Polycarbonate Nanocomposites Part 2. Degradation and Color Formation. Polymer 2003, 44, 5341-5354. [CrossRef]

35. Nevalainen, K.; Vuorinen, J.; Villman, V. Characterization of Twin-Screw-Extruder-Compounded Polycarbonate Nanoclay Composites. Polym. Eng. Sci. 2009, 49, 631-640. [CrossRef]

36. Feng, J.; Hao, J.; Du, J.; Yang, R. Effects of Organoclay Modifiers on the Flammability, Thermal and Mechanical Properties of polycarbonate Nanocomposites filled with a Phosphate and Organoclays. Polym. Degrad. Stab. 2012, 97, 108-117. [CrossRef]

37. Nayak, S.K.; Mohanty, S.; Samal, S.K. Mechanical and Thermal Properties Enhancement of Polycarbonate Nanocomposites Prepared by Melt Compounding. J. Appl. Polym. Sci. 2010, 117, 2101. [CrossRef]

38. Feyz, E.; Jahani, Y.; Esfandeh, M. Effect of a Nanoclay/Triphenyl Phosphate Hybrid System on the Fire Retardancy of Polycarbonate/Acrylonitrile-Butadiene-Styrene Blend. J. Appl. Polym. Sci. 2011, 120, 3435. [CrossRef]

39. Table Curve 3D, Systat Software, Inc. Available online: http://www.systat (accessed on 11 December 2019).

40. Hirayama, D.; Saron, C. Characterisation of recycled acrylonitrile-butadiene-styrene and high-impact polystyrene from waste computer equipment from Brazil. Waste Manag. Res. 2015, 33, 543-549. [CrossRef]

41. Beigbeder, J.; Perrin, D.; Mascaro, J.F.; Lopez-Cuesta, J.M. Study of the physico-chemical properties of recycled polymers from waste electrical and electronic equipment (WEEE) sorted by high resolution near infrared devices. Conserv. Recycl. 2013, 78, 105-114. [CrossRef]

42. Du, X.; Yu, H.; Wang, Z.; Tang, T. Effect of anionic organoclay with special aggregate structure on the flame retardancy of acrylonitrile-butadiene-styrene/clay composites. Polym. Degrad. Stab. 2010, 95, 587-592. [CrossRef]

43. Zhang, J.; Jiang, D.D.; Wang, D.; Wilkie, C.A. Styrenic polimer nanocomposites based on a aligomericallymodified clay with high inorganic content. Polym. Degrad. Stab. 2006, 91, 2665-2674. [CrossRef]

44. Wang, S.; Hu, Y.; Song, L.; Wang, Z.; Chen, Z.; Fan, W. Preparation and thermal properties of ABS/montmorillonite nanocomposite. Polym. Degrad. Stab. 2002, 77, 423-426. [CrossRef]

45. Zhang, Y.; Chen, X.; Fang, Z. Flame retardant ABS with a novel polyphosphate derived from biomass. Adv. Mater. Res. 2011, 284-286, 187-192. [CrossRef]

46. Wu, N.; Li, X. Flame retardancy and synergistic flame retardant mechanisms of acrylonitrile-butadiene-styrene composites based on aluminum hypophosphite. Polym. Degrad. Stab. 2014, 105, 265-276. [CrossRef]

47. Marcilla, A.; Garcia Quesada, J.C.; Gomez-Siurana, A.; Berenguer, D. Characterization of styrene-butadiene copolymers by catalytic pyrolysis over Al-MCM-41. J. Anal. Appl. Pyrol. 2009, 85, 327-333. [CrossRef]

48. Mattausch, H. Properties and applications of nanoclay composites. In Polymer Nanoclay Composites; Elsevier: Amsterdam, The Netherlands, 2015; pp. 127-155.

49. Simionescu, T.M.; Minea, A.A. The effect of montmorillonite clay and fire retardants on the heat of combustion of recycled acrylonitrile-butadiene styrene. Environ. Eng. Manag. J. 2019, 18, 317-326.

50. Zhuge, J.; Tang, Y.; Chen, R.-H.; Ibeh, C.; Hu, Y. Flammability of carbon nanofiber-clay nano paper based polymer composites. Polym. Adv. Technol. 2011, 22, 1403-1413. [CrossRef]

51. Ahmed, L.; Zhang, B.; Hawkins, S.; Mannan, M.S.; Cheng, Z. Study of thermal and mechanical behaviors of flame retardant polystyrene-based nanocomposites prepared via in-situ polymerization method. J. Loss Prev. Process 2017, 49, 228-239. [CrossRef]

52. Wang, L.; He, X.; Wilkie, C.A. The utility of Nanocomposites in fire retardancy. Materials 2010, 3, 4580-4606. [CrossRef]

(C) 2019 by the authors. Licensee MDPI, Basel, Switzerland. This article is an open access article distributed under the terms and conditions of the Creative Commons Attribution (CC BY) license (http://creativecommons.org/licenses/by/4.0/). 